\title{
Refining of Buriti Oil (Mauritia flexuosa) Originated from the Brazilian Cerrado: Physicochemical, Thermal-Oxidative and Nutritional Implications
}

\author{
Jailane de Souza Aquino, ${ }^{*, a}$ Débora C. N. de Pontes Pessoa, ${ }^{b}$ Kassandra de Lourdes G. V. Araújo, ${ }^{c}$ \\ Poliana S. Epaminondas, ${ }^{d}$ Alexandre Ricardo P. Schuler, ${ }^{e}$ Antônio G. de Souza ${ }^{f}$ and \\ Tânia Lúcia M. Stamford ${ }^{b}$
}

${ }^{a}$ Departamento de Nutrição (CCS), ${ }^{c}$ Departamento de Ciência e Tecnologia de Alimentos and ${ }^{f}$ Departamento de Química (CCEN), Universidade Federal da Paraíba, Campus I, Cidade Universitária, s/n, Castelo Branco, 58051-900 João Pessoa-PB, Brazil

${ }^{b}$ Departamento de Nutrição (CCS) and ${ }^{e}$ Departamento de Engenharia Química (CTG), Universidade Federal de Pernambuco, Campus Recife, s/n, Cidade Universitária, 50670901 Recife-PE, Brazil

${ }^{d}$ Setor de Agroindústria, Instituto Federal de Educação, Ciência e Tecnologia (IFPB), Campus Sousa, Jardim Sorrilândia, 58800-970 Sousa-PB, Brazil

\begin{abstract}
Objetivou-se comparar os parâmetros físico-químicos e termo-oxidativos do óleo bruto de buriti com o refinado, como também determinar o teor de vitamina A, perfil lipídico e potencial antioxidante destes óleos. Amostras de óleo bruto e refinado foram avaliadas quanto à viscosidade, densidade relativa, índices de refração, acidez, ácidos graxos livres, peróxido e de iodo, grau de oxidação lipídica por UV-Vis, termogravimetria, calorimetria, capacidade antioxidante, teor de vitamina A e perfil de ácidos graxos. O refino do óleo diminuiu o percentual de ácidos graxos livres e os índices de acidez, de iodo e de peróxido, apresentando maior estabilidade termo-oxidativa que o óleo bruto. Porém sua capacidade antioxidante, o teor de vitamina A e o de ácidos graxos insaturados foram reduzidos em relação ao óleo bruto. Logo, sugere-se a otimização do processo de refino para minimizar perdas nutricionais no óleo de buriti, que por suas características pode ser considerado um alimento funcional.
\end{abstract}

The objective of this study was to compare the physicochemical, thermo-oxidative and nutritional characteristics of crude and refined buriti oil. Crude and refined oil samples were evaluated for viscosity, relative density, refraction, acidity, free fatty acids, peroxide and iodine, lipid oxidation degree by UV-Vis, thermogravimetry, calorimetry, in vitro antioxidant capacity, vitamin A content and fatty acids profile. The refining process decreased the free fatty acids percentage and acidity, peroxide and iodine indexes, with greater thermal-oxidative stability, which is critical for its use in cooking food. However, its antioxidant capacity, vitamin A and unsaturated fatty acids contents were reduced compared to crude oil. Therefore, it is suggested to optimize the refining process to minimize nutritional losses in buriti oil, which due to its characteristics, can be considered a functional food.

Keywords: antioxidants, buriti oil, carotenes, fatty acids, oxidative stability, refined oil

\section{Introduction}

Vegetable oils are used in industrial products such as margarine, vegetable creams, salad dressings, mayonnaise, and also in foods manually prepared, ${ }^{1}$ contributing to flavor, appearance and creamy texture of foods. ${ }^{2}$ There has been

*e-mail: lalaaquino@hotmail.com and increasing demand for vegetable oils with special composition such as olive, sunflower, palm and linseed oils, which have shown high commercial value due to the presence of functional components. ${ }^{1}$

Buriti oil (Mauritia flexuosa) has functional properties due to its high concentration of monounsaturated fatty acids (MUFA), nutrient with hypocholesterolemic action. ${ }^{3}$ In addition, it has tocopherols ${ }^{4}$ and carotenes, ${ }^{5}$ which are 
nutritionally important and well recognized as antioxidants ${ }^{6}$ and pro-vitamin A. ${ }^{7}$

The antioxidant properties of vegetable oils have been widely studied due to the health benefits to consumers and their use in the food industry. ${ }^{6,8}$ The oxidative stability of a vegetable oil can be influenced by the amount of antioxidants naturally present or added to this product. ${ }^{9}$

The composition and consequently the nutritional value of crude buriti oil may vary with season and extraction process. Improper post-harvest handling of this fruit may lead to decreased smoke point, oxidation of vitamins and high acidity levels (hydrolysis of triacylglycerols), which reduces the oxidative stability of this oil. ${ }^{10}$ In this context, the refining of crude vegetable oils should be performed, which includes degumming, neutralization, clarification and deodorization steps, ${ }^{11}$ resulting in a product with desirable physicochemical, nutritional and sensory characteristics.

Due to the use of crude buriti oil in foods, cosmetics, drugs, ${ }^{12}$ in polymeric materials,,${ }^{13,14}$ among others, this study aimed to compare the physicochemical and thermooxidative characteristics of crude and refined buriti oils and also determine the vitamin A content, lipid profile and antioxidant potential of these oils.

\section{Experimental}

Material

Crude buriti oil was purchased in the local trade of the city of Picos-PI, Brazil. Oil samples were manually extracted from ripe fruits by boiling in water for $20 \mathrm{~min}$ at $\pm 60^{\circ} \mathrm{C}$, then separating the oily fraction from the aqueous fraction. For all experiments, $10 \mathrm{~L}$ of crude oil from different batches were used, and for each liter of oil aimed at refining, $200 \mathrm{~mL}$ were stored and $800 \mathrm{~mL}$ were refined for comparison of the physicochemical, thermo-oxidative and nutritional characteristics between samples before and after the refining process.

\section{Extracting and refining processes}

Crude buriti oil was refined according to degumming, neutralization, washing and drying steps. The oil underwent degumming process by adding $3.0 \%$ of water in relation to the oil mass, with subsequent heating at $60{ }^{\circ} \mathrm{C}$ and stirring for $30 \mathrm{~min}$, in accordance with methodology proposed by Moretto and Fett. ${ }^{15}$

Then, the oil was neutralized using methodology of Morais et al..$^{16}$ at temperature of $50{ }^{\circ} \mathrm{C}$ and stirring for 30 min, by adding $5.0 \%$ of sodium hydroxide solution in relation to the oil mass, and this solution had concentration of $12 \%$. Subsequently, the oil was centrifuged at $5000 \mathrm{rpm}$ for the removal of solid impurities from the product. Soon after, the oil was transferred to a separatory funnel where successive washes were performed. The washings were carried out at intervals of $30 \mathrm{~min}$ each, and the neutralized oil was added of water at room temperature and water at temperature of $90-95^{\circ} \mathrm{C}$ in rotation, always submitting it to manual shaking in the separatory and gas removal funnel. In each washing step, after the separation phase, the water was discarded and phenolphthalein was added and then, in the last wash, bromothymol green was added in order to detect any trace of sodium hydroxide used in neutralization. The washings continued until the indicators no longer detected alkalinity in the water.

The oil was dried in a rotary evaporator at $60{ }^{\circ} \mathrm{C}$ with vacuum pressure for $20 \mathrm{~min}$ under mild agitation and cooled. These oil samples were stored in amber glass containers with capacity of $1 \mathrm{~L}$ each, properly coded and kept under refrigeration between 7 and $10{ }^{\circ} \mathrm{C}$.

\section{Physicochemical and thermal analyses}

The physicochemical evaluation of crude and refined buriti oils consisted of determining viscosity, relative density, refractive index,${ }^{17}$ acidity index, free fatty acids, peroxide index, iodine index, lipid oxidation level by spectroscopy at the UV-Vis region in spectrometer model UV-2550 Shimadzu, with wavelengths between 200 and $900 \mathrm{~nm}$, using $1 \mu \mathrm{L}$ oil diluted in dichloromethane. ${ }^{18}$

The thermogravimetric (TG) and calorimetric curves (DSC - differential scanning calorimetry) were obtained using analyzer SDT 2960 (TA Instruments) and thermal analyzer DSC 2920 (TA Instruments), respectively. The non-isothermal method was applied using $10 \mathrm{mg}$ of sample heated at $10^{\circ} \mathrm{C} \mathrm{min}^{-1}$ up to $900{ }^{\circ} \mathrm{C}$, for TG, and up to $600{ }^{\circ} \mathrm{C}$ for DSC. Analyses were performed using platinum sample holder and synthetic air at flow rate of $110 \mathrm{~mL} \mathrm{~min}^{-1}$. The onset oxidation temperature was obtained ( $\left.\mathrm{OT}_{\text {onset }}\right)$, which is the temperature corresponding to the sudden increase in oxidation products, as well as the initial oxidation temperature $\left(\mathrm{OT}_{\mathrm{i}}\right)$, corresponding to the beginning of oxidation.

\section{Lipid profile}

Initially, the lipid extract was obtained by the method of Folch et al. ${ }^{19}$ From this extract, the methyl esters were obtained by esterification carried out in accordance with the method of Hartman and Lago. ${ }^{20}$ The identification and quantification of methyl esters were performed using gas chromatograph label Ciola \& Gregori Ltda 
(model CG-Master) with flame ionization detector. The chromatographic conditions were: polyethylene glycol column (Carbowax 20M) made of fused silica $30 \mathrm{~m}$ long, $0.53 \mathrm{~mm}$ in diameter and $0.25 \mu \mathrm{m}$ of film thickness of stationary phase. The temperatures used were 150 and $200{ }^{\circ} \mathrm{C}$ for vaporizer and detector, respectively. The furnace programming consisted of the following operation sequence: $80{ }^{\circ} \mathrm{C}$ for $3 \mathrm{~min}$, increasing $10{ }^{\circ} \mathrm{C} \mathrm{min}-1$ up to $120^{\circ} \mathrm{C}$, remaining at $200^{\circ} \mathrm{C}$ for $6 \mathrm{~min}$, and then decreasing $3{ }^{\circ} \mathrm{C} \mathrm{min}-1$ up to $180{ }^{\circ} \mathrm{C}$. The mobile phase was hydrogen,

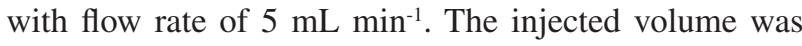
$1 \mu \mathrm{L}$, with split ratio of $1: 25$. The fatty acids profile characterization was performed by comparison of the mass spectra obtained with that of standards that were also injected into the GC-MS.

\section{Vitamin A determination}

Samples were cold saponified with $10 \%$ potassium hydroxide solution in methanol. The extract was added of petroleum ether and washed with water until neutral $\mathrm{pH}$, then the volume was adjusted and the extract was filtered through a $0.45 \mu \mathrm{L}$ membrane for injection. The beta carotene identification and quantification was performed in a Shimadzu class 10 HPLC with diode array and manual injector and wavelength of $450 \mathrm{~nm}$. The chromatographic conditions were: lichrospher 100 RP column (Merck), C18, $125 \mathrm{~m}$ long, $4 \mathrm{~mm}$ in diameter and $5 \mu \mathrm{m}$ of film thickness of stationary phase. The mobile phase was methanol: chloroform (95:5), at flow rate of $1 \mathrm{~mL} \mathrm{~min}^{-1}$. The injected volume was $200 \mu \mathrm{L}$. The beta carotene result was converted into vitamin A using factor $1.8 .^{21}$

\section{Antioxidant potential of in vitro crude and refined buriti oils}

For this analysis, the extract was prepared from $5 \mathrm{~g}$ of oil was added of $40 \mathrm{~mL}$ of hexane, the resulting suspension was homogenized and left to rest for $60 \mathrm{~min}$ at room temperature. The mixture was centrifuged at $15.000 \mathrm{rpm}$ for $15 \mathrm{~min}$ and the supernatant transferred to a $100 \mathrm{~mL}$ volumetric flask. From the residue after the first extraction, $40 \mathrm{~mL}$ of $70 \%$ acetone were added, homogenized and left to rest for $60 \mathrm{~min}$ at room temperature. Subsequently, the sample was once again centrifuged at $15.000 \mathrm{rpm}$ for $15 \mathrm{~min}$ and the supernatant was transferred to the flask containing the first supernatant, and the volume was completed to $100 \mathrm{~mL}$ with distilled water.

Different extract concentrations were used in the evaluation $\left(0.4 ; 1.0 ; 2.0 ; 3.0\right.$ and $\left.4.0 \mathrm{mg} \mathrm{mL}^{-1}\right)$. Aliquot of $0.1 \mathrm{~mL}$ of extract at different concentrations, was added to $3.9 \mathrm{~mL}$ of DPPH' methanol solution $\left(60 \mu \mathrm{mol} \mathrm{L} \mathrm{L}^{-1}\right)$. The mixture was homogenized and incubated in the dark for $30 \mathrm{~min}$. The results were read at $517 \mathrm{~nm}$ on Shimadzu UV-Vis spectrophotometer model 1650-PC. Methyl alcohol was used as white to calibrate the spectrophotometer. ${ }^{22}$ Carduus marianus and catechin solutions were used as antioxidant standards in the same concentration as that of the extract. Analyses were performed in triplicate and the results expressed in \% scavenging of free radicals (SFR), using the following equation

SFR $\%=\left(\frac{A b s w-A b s ~ s}{A b s w}\right) \times 100$

where, SFR = \% scavenging of free radicals, Abs $w=$ control absorbance (DPPH without test substance) and Abs s = sample absorbance.

The $\mathrm{IC}_{50}$ value was calculated based on the final concentration in $\mathrm{mg} \mathrm{mL}^{-1}$ of dry extract required to decrease the initial DPPH concentration by $50 \% .^{23}$

\section{Statistical analysis}

Statistical analysis was performed using the SPSS (SPSS INC. 14.0 for Windows Evaluation Version). ${ }^{24}$ Averages were submitted to the $t$-Student test, $\mathrm{p} \leq 0.05$ was considered statistically significant.

\section{Results and Discussion}

Physicochemical and thermal analyses

Table 1 shows the comparison between the physicochemical characteristics of crude and refined buriti oils. The crude buriti oil showed higher density, higher percentage of free fatty acids, higher acidity, peroxide and iodine indexes $(\mathrm{p} \leq 0.05)$.

Table 1. Physicochemical characterization of crude and refined buriti oils

\begin{tabular}{lcc}
\hline & \multicolumn{2}{c}{ Samples } \\
\cline { 2 - 3 } Variables & Crude buriti oil & Refined buriti oil \\
\cline { 2 - 3 } & $\begin{array}{c}\text { Average } \pm \text { standard } \\
\text { deviation }\end{array}$ & $\begin{array}{c}\text { Average } \pm \text { standard } \\
\text { deviation }\end{array}$ \\
\hline Viscosity / $\left(\mathrm{mm}^{2} \mathrm{~s}^{-1}\right)$ & $43.29^{\mathrm{a}} \pm 1.45$ & $42.31^{\mathrm{a}} \pm 2.50$ \\
Density / $\left(\mathrm{mg} \mathrm{mL}^{-1}\right)$ & $0.92^{\mathrm{a}} \pm 0.02$ & $0.90^{\mathrm{b}} \pm 0.02$ \\
Refractive index & $1.47^{\mathrm{a}} \pm 0.00$ & $1.47^{\mathrm{a}} \pm 0.00$ \\
Free fatty acids / $\%$ & $4.30^{\mathrm{a}} \pm 0.31$ & $0.31^{\mathrm{b}} \pm 0.04$ \\
Acidity index / $\%$ & $4.27^{\mathrm{a}} \pm 0.43$ & $0.21^{\mathrm{b}} \pm 0.04$ \\
Peroxide index / & $14.82^{\mathrm{a}} \pm 0.72$ & $7.80^{\mathrm{b}} \pm 0.91$ \\
(mequiv. $\left.\mathrm{kg}^{-1}\right)$ & & \\
Iodine index & $90.00^{\mathrm{a}} \pm 0.54$ & $81.10^{\mathrm{b}} \pm 0.32$ \\
\hline
\end{tabular}

Different letters on same row represent significant difference at $5 \%$ level by $t$-Student test. 
In a study by Silva et al. ${ }^{10}$ the acidity of refined buriti oil ranged from 2.01 to 6.22 and crude buriti oil from 1.14 to 1.77 , whose results are different from those obtained in this study. The higher the acidity of the crude oil, the greater the losses of pigments will be, since greater amounts of $\mathrm{NaOH}$ will be required in the neutralization step during the refining process. According to Del Rio et al. ${ }^{25}$ sunflower $(0.08 \%)$ and soybeans oils $(0.082 \%)$ had lower acidity than the refined buriti oil $(0.21 \%)$, which in turn was similar to that obtained for palm oil $(0.27 \%)$ by the same authors. The acidity index may vary depending on the maturity of the vegetable from which the oil is extracted ${ }^{26}$ on thermal treatments ${ }^{27}$ and on refining process. ${ }^{25}$

According to Ribeiro et al.,$^{28}$ the maximum free fatty acids content should be $5 \%$ for crude buriti oil and $1 \%$ for refined buriti oil, and it was observed that the oils analyzed in this study are within the standards recommended. During the refining process, the free fatty acids content must be reduced to an acceptable level recommended by current legislation, and this occurred after the refining process. Free fatty acids occur naturally in crude oils and their content can rise during storage or handling. Some crude oils have higher free fatty acids contents due to enzymatic hydrolysis or poor conditions during transport and/or storage of grains. The FFA (free fatty acids) content is good indicator of the quality of crude and refined oils. ${ }^{29}$

The iodine index measures the degree of unsaturation of oils, revealing that there was degradation of unsaturated fatty acids during the refining process. Nevertheless, both samples showed acceptable iodine index between 115 and 150 for crude oil and between 80 and 150 for refined buriti oil. ${ }^{30}$ The refractive index of 1.47 and density between 0.90 and $0.92 \mathrm{mg} \mathrm{mL}^{-1}$ were very close to values obtained by García-Quiroz et al. ${ }^{30}$ and by Silva et al. ${ }^{10}$ for a blend of homemade and industrialized oils.

There was a 50\% reduction in the peroxide index of crude buriti oil after refining, and these results are satisfactory according to the CodexAlimentarius, which establishes that peroxide index values of up to 15 mequiv. $\mathrm{kg}^{-1}$ for unrefined oils are acceptable, since at this stage, the rancidity taste is noticeable. ${ }^{31}$ However, according to parameters reported by Ribeiro et al. ${ }^{28}$ and Shahidi, ${ }^{32}$ the maximum peroxide index for crude oil must be 10 mequiv. $\mathrm{kg}^{-1}$ and for refined buriti oil 7 mequiv. $\mathrm{kg}^{-1}$.

Figure 1 shows the UV-Vis absorbance spectra, with a high absorption in the spectral region between 280 and $360 \mathrm{~nm}$, which increases with the thermal oxidation of oils.

These absorption regions can be attributed to the oxidation of the oils tested, since the primary compounds from the oxidation process show absorbance regions around 240 and $320 \mathrm{~nm}$ (conjugated dienes). Furthermore,

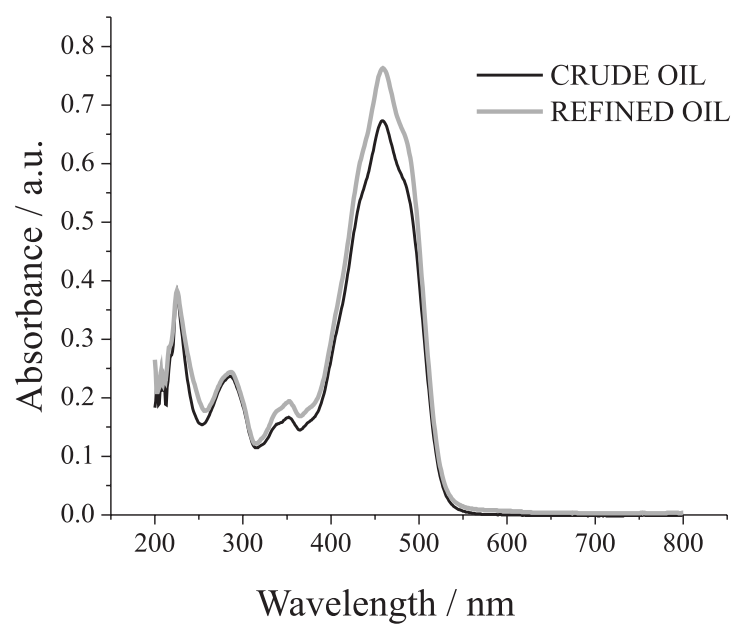

Figure 1. Absorption spectra of buriti oils in UV-Vis.

secondary compounds (trienes, aldehydes, $\beta$-unsaturated, conjugated $\alpha$ ketones) have absorption peaks around 280 and $320 \mathrm{~nm} \cdot{ }^{33}$ In oils, when there is any type of change, as that induced by thermal oxidation, for example, the generated spectrum shows a band shift (bathochromic effect) and increased absorption intensity. ${ }^{34}$ This result may be associated with a decrease of the iodine index previously reported (Table 1), showing the importance of combining analytical techniques in the search for more accurate results.

A higher absorption peak of about $459 \mathrm{~nm}$ could be observed in the refined buriti oil due to oxidative cleavage of carotenoids into apocarotenoids during the refining process ${ }^{28}$ which showed absorbance regions around 410 and $476 \mathrm{~nm}^{35}$

It was found that crude and refined buriti oil samples showed similar TG profiles, with three common steps of mass variation (Table 2 and Figure 2a).

The DSC curves (Figure 2), as well as data extracted from these curves (Table 2) highlight the oxidation temperatures (OT). In this study, it was chosen to determine the oxidative stability of buriti oils from the initial oxidation temperature $\left(\mathrm{OT}_{\mathrm{i}}\right)$, since in the case of products for food production, it is more convenient to consider parameters corresponding to the onset of the oxidation process than those related to the stage where there is a sudden increase in the formation of oxidation products (onset oxidation temperature obtained from the extrapolation of the tangent to the curve).

A difference in oxidative stability between crude and refined buriti oils was observed, considering the results of $\mathrm{OT}_{\mathrm{i}}$ of $196{ }^{\circ} \mathrm{C}$ and $\mathrm{OT}_{\mathrm{i}}$ of $203{ }^{\circ} \mathrm{C}$, respectively, which determined the onset of the oxidation process. Refined buriti oils had higher OT and are more stable due to the formation of compounds of greater stability, resulting 
Table 2. Thermogravimetric and calorimetric data of buriti oil samples in an oxidizing atmosphere (synthetic air)

\begin{tabular}{|c|c|c|c|c|c|c|c|c|}
\hline \multirow{2}{*}{ Samples } & & \multicolumn{5}{|c|}{ TG } & \multicolumn{2}{|c|}{ DSC } \\
\hline & & Step & $\mathrm{T}_{\text {initial }} /{ }^{\circ} \mathrm{C}$ & $\mathrm{T}_{\text {final }} /{ }^{\circ} \mathrm{C}$ & $\mathrm{T}_{\text {peak }}$ DTG $/{ }^{\circ} \mathrm{C}$ & $\Delta \mathrm{m}^{\mathrm{a}} / \%$ & $\mathrm{OT}_{\mathrm{i}}^{\mathrm{b}} /{ }^{\circ} \mathrm{C}$ & $\mathrm{OT}_{\text {onset }}{ }^{\mathrm{c}} /{ }^{\circ} \mathrm{C}$ \\
\hline \multirow{6}{*}{ Buriti oils } & \multirow{3}{*}{ Crude } & $1^{\mathrm{st}}$ & 174 & 372 & 352 & 48 & \multirow{3}{*}{196} & \multirow{3}{*}{223} \\
\hline & & $2^{\text {nd }}$ & 372 & 469 & 421 & 40 & & \\
\hline & & $3^{\text {rd }}$ & 469 & 560 & 560 & 12 & & \\
\hline & \multirow{3}{*}{ Refined } & $1^{\mathrm{st}}$ & 232 & 375 & 361 & 51 & \multirow{3}{*}{203} & \multirow{3}{*}{263} \\
\hline & & $2^{\text {nd }}$ & 375 & 475 & 419 & 37 & & \\
\hline & & $3^{\text {rd }}$ & 475 & 573 & 532 & 12 & & \\
\hline
\end{tabular}

${ }^{\mathrm{a}}$ mass loss, binitial oxidation temperature and ${ }^{\mathrm{c}}$ oxidation temperature.
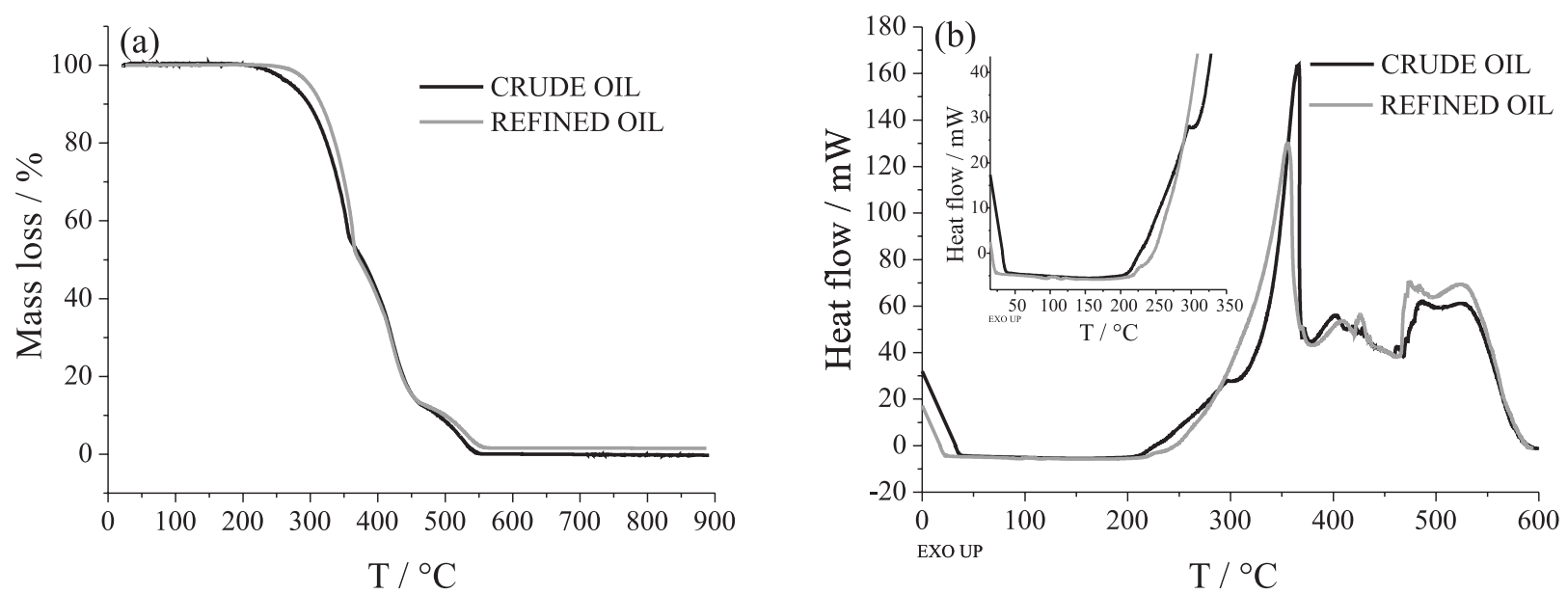

Figure 2. Thermogravimetric (a) and calorimetric curves (b) for crude and refined buriti oil samples.

from the reduction in the free fatty acids contents after the refining process, as discussed in the physicochemical analysis (Table 1). Besides the reduction in the free fatty acids contents, the refining process is aimed at removing other impurities such as phospholipids and pigments, ${ }^{36}$ despite the favorable antioxidant action of some pigments such as carotenoids and tocopherols of natural occurrence in these oils.

Oxidation propagation temperatures $\left(\mathrm{OT}_{\text {onset }}\right)$ were lower for crude buriti oils, corroborating the greater thermo-oxidative fragility of crude oils compared to refined oils. Tan et al. ${ }^{37}$ analyzed the oxidative stability of oil samples with high polyunsaturated fatty acids content such as olive, corn, sunflower, peanut and soybean oils, among others, with $\mathrm{OT}_{\text {onset }}$ of $169,167,132,127$ and $124{ }^{\circ} \mathrm{C}$, respectively, in pure oxygen atmosphere and other analytical conditions similar to those in this study, and observed that the oxidation propagation temperatures $\left(\mathrm{OT}_{\text {onset }}\right)$ were higher for both crude and refined buriti oil samples, showing the higher oxidative stability of buriti oils over other vegetable oils. Pardauil et al..$^{38}$ evaluated the oxidative stability of buriti oil using DSC and Rancimat techniques and found that buriti oil is highly stable and is very useful for the food industry.

\section{Lipid profile}

Table 3 shows the fatty acid composition of crude and refined buriti oils. A decrease in the amount of unsaturated fatty acids and an increase in the saturated fatty acids contents were observed after the refining process, which was also confirmed by the decrease of the iodine index (Table 1). It is suggested that the neutralization and washing steps may interfere with the breaking of double bonds, since unsaturated fatty acids are more reactive and more susceptible to oxidation. ${ }^{39}$

The fatty acid composition results of crude and refined buriti oils corroborate those found by Schlemmer and Sales ${ }^{14}$ and Albuquerque et al. ${ }^{4}$ who observed in crude buriti oil, $2 \%$ of stearic acid, 73.3 to $78.73 \%$ of oleic acid, $2.4 \%$ of linoleic acid, and $2.20 \%$ of linolenic acid. Higher linoleic acid values $(4.94 \%)$ were found in the buriti oil by Silva et al. ${ }^{10}$ and Ceriani et al..$^{41}$ This variation in results may be influenced by season, extraction and refining processes. Moreover, buriti oil showed a high unsaturated fatty acids content (over 90\%), being suitable as functional food as reported by Ribeiro. ${ }^{28}$

The buriti oil is classified as an oleic oil, which is the same as olive oil, canola oil and peanut oil, since this 
Table 3. Fatty acids present in crude and refined buriti oils

\begin{tabular}{lcc}
\hline \multirow{2}{*}{ Fatty acids } & \multicolumn{2}{c}{ Samples } \\
\cline { 2 - 3 } & $\begin{array}{c}\text { Crude } \\
\text { buriti oil }\end{array}$ & $\begin{array}{c}\text { Refined } \\
\text { buriti oil }\end{array}$ \\
\hline Miristic acid - C 14:0 & $0.5^{\mathrm{a}}$ & $0.5^{\mathrm{a}}$ \\
Margaric acid - C 17:0 & $0.3^{\mathrm{a}}$ & $0.2^{\mathrm{a}}$ \\
Stearic acid - C18:0 & $2.3^{\mathrm{a}}$ & $3.9^{\mathrm{b}}$ \\
Total saturated fatty acids - SFA / \% & $3.1^{\mathrm{b}}$ & $4.6^{\mathrm{a}}$ \\
Palmitoleic acid - C16:0 & $19.6^{\mathrm{a}}$ & $19.4^{\mathrm{a}}$ \\
Oleic acid - C18:1 & $72.7^{\mathrm{a}}$ & $72.2^{\mathrm{b}}$ \\
Total monounsaturated fatty acids - & $92.3^{\mathrm{a}}$ & $91.6^{\mathrm{a}}$ \\
MUFA / \% & & \\
Linoleic acid - C 18:2 & $2.6^{\mathrm{a}}$ & $2.3^{\mathrm{b}}$ \\
Linolenic acid - C 18:3 & $2.0^{\mathrm{a}}$ & $1.5^{\mathrm{b}}$ \\
Total polyunsaturated fatty acids - PUFA / \% & $4.6^{\mathrm{a}}$ & $3.8^{\mathrm{a}}$ \\
\hline
\end{tabular}

Different letters on same row represent significant difference at $5 \%$ level by $t$-Student test. The values are expressed in percentage $(\%)$.

fatty acid is present in quite high amounts, about $75 \%$ in buriti oil. ${ }^{4}$ However, it could be observed that the buriti oil analyzed has monounsaturated fatty acid content higher than olive oil and Brazil nut oil, widely recognized by its capacity of favorably changing the lipid profile, reducing total cholesterol, LDL cholesterol and triglycerides, preventing cardiovascular diseases. ${ }^{3}$ Moreover, the saturated fatty acids content is comparable to olive oil, soybean oil and Brazil nut oil. It is noteworthy that the fatty acids composition reported in this study for refined buriti oil is the first report in literature.

\section{Vitamin A determination}

A statistically significant decrease $(\mathrm{p} \leq 0.05)$ in vitamin $\mathrm{A}$ and beta carotene contents of refined oil in relation to crude oil was observed in this study. Crude buriti oil showed $50.636 \mathrm{IU}$ of vitamin A and $911.4 \pm 2.4 \mathrm{mg} \mathrm{kg}^{-1}$ of beta carotene, while refined buriti oil showed $44.006 \mathrm{IU}$ of vitamin A and $792.1 \pm 4.54 \mathrm{mg} \mathrm{kg}^{-1}$ of beta carotene. According to Gunstone, ${ }^{36}$ during the refining process, unsaponifiables are partially removed or degraded during neutralization, bleaching and deodorizing stages. According to Ribeiro et al. ${ }^{28}$ in the degradation of carotenoids, $\beta$-carotene is transformed into apocarotenoids, especially 10 -apo- $\beta$-carotenal, which explains the reduced vitamin A and carotenoid contents in crude buriti oil compared to refined buriti oil. However, the apocarotenoid formed could be used in the manufacturing of margarine as a substitute for synthetic dyes such as canthaxanthin and 8-apo- $\beta$ carotenal. This fact was also observed in the absorption spectra of UV-Vis, which was confirmed by the decrease in carotenoids.
The carotenoid contents determined by HPLC in this study was higher for refined oil samples than those reported by Silva et al. ${ }^{10}$ which ranged from 252 to $664 \mathrm{mg} \mathrm{kg}^{-1}$ for industrialized buriti oil, using the same technique. However, the carotenoid contents found in this study for crude buriti oil were lower than $1706 \pm 54 \mathrm{mg} \mathrm{kg}^{-1}$ reported by Garcia-Quiroz et al. ${ }^{30}$ and $1700 \mathrm{mg} \mathrm{kg}^{-1}$ reported by Albuquerque et al. , $^{40}$ both carried out by spectrophotometry and similar to that reported by Silva et al. ${ }^{10}$ which averaged $900 \pm 10 \mathrm{mg} \mathrm{kg}^{-1}$ of carotenoids for homemade buriti oil, determined by HPLC.

Even with the decrease in vitamin $\mathrm{A}$ and carotenoid contents from crude to refined buriti oils, this level still exceeds the carotenoid contents of tucumã, bocaiuva bacuri and umari (mari) palm fruits, because, according to Rodriguez-Amaya, ${ }^{42}$ buriti is the food product showing the highest known beta carotene concentration among the wide range of Brazilian foods already analyzed.

\section{Antioxidant potential}

The potential of crude and refined buriti oils to scavenge free radicals was expressed as the final extract concentration required to inhibit the oxidation of the DPPH radical by $50 \%\left(\mathrm{IC}_{50}\right)$, and results are shown in Table 4.

Table 4. Antioxidant activities of crude and refined Buriti oils

\begin{tabular}{lc}
\hline \multirow{2}{*}{ Buriti oils } & Radical DPPH scavenging activity \\
\cline { 2 - 2 } & $\mathrm{IC}_{50} /\left(\mathrm{mg} \mathrm{mL}^{-1}\right)$ \\
\hline Crude & $25.19 \pm 5.42^{\mathrm{b}}$ \\
Refined & $50.98 \pm 3.31^{\mathrm{a}}$ \\
\hline
\end{tabular}

Value expressed in means \pm standard derivation. Different letters on same row represent significant difference at $5 \%$ level by $t$-Student test. $\mathrm{IC}_{50}=$ concentration required to inhibit the oxidation of the DPPH radical by $50 \%$.

The lowest $\mathrm{IC}_{50}$ values were obtained in crude buriti oils, indicating a higher antioxidant potential in relation to refined oils. An extract showing high potential to scavenge free radicals has low $\mathrm{IC}_{50}{ }^{23}$ It was observed that crude buriti oil showed lower $\mathrm{IC}_{50}$ when compared to corn, sunflower and soybean oils analyzed by Valavanidis et al., ${ }^{43}$ thus showing higher antioxidant activity than these oils. However, it showed higher $\mathrm{IC}_{50}$ when compared to olive oil, thus showing lower antioxidant activity than the same.

Refined buriti oil showed higher antioxidant activity than soybean oil $\left(\mathrm{IC}_{50}=52 \mathrm{mg} \mathrm{mL}^{-1}\right)$ and lower antioxidant activity compared to in natura sunflower, corn and olive oils, which showed $\mathrm{IC}_{50}$ of 45,48 and $22 \mathrm{mg} \mathrm{mL}^{-1}$, respectively. ${ }^{43}$ This is explained by losses of antioxidants 
such as flavonoids, tocopherols and vitamin $\mathrm{A}^{44}$ during the refining process, which should be controlled by the food industry since there is a tendency to even greater losses of antioxidants during the heating of oils, i.e., at frying or baking temperatures. ${ }^{43}$

\section{Conclusions}

The analytical techniques used in this study complemented each other, and it could be inferred that the refining process of buriti oil decreased the amounts of vitamin A, unsaturated fatty acids and its antioxidant activity in relation to crude buriti oil. Nevertheless, an improvement in physicochemical characteristics of the refined oil was observed, providing it high thermal-oxidative stability against oils usually edible. Therefore, the refining process should be improved to minimize nutritional losses in buriti oil, which can be considered a functional food.

\section{References}

1. Foster, R.; Williamson, C. S.; Lunn, J.; Nutr. Bull. 2009, 34, 4.

2. Saberi, A. H.; Kee, B. B.; Oi-Ming, L.; Miskandar, M. S.; Food Chem. 2011, 127, 1031.

3. Binkoski, A. E.; Kris-Etherton, P. M.; Wilson, T. A.; Mountain, M. L.; Nicolosi, R. J.; J. Am. Diet. Assoc. 2005, 105, 1080.

4. Albuquerque, M. L. S.; Guedes, I.; Alcantara Jr., P.; Moreira, S. G. C.; Barbosa Neto, N. M.; Correa, D. S.; Zilio, S. C.; J. Braz. Chem. Soc. 2005, 16, 1113.

5. De Rosso, V. V.; Mercadante, A. Z.; J. Agric. Food Chem. 2007, 55,5062 .

6. Sem, C. K.; Khanna, S.; Roy, S.; Life Sci. 2006, 78, 2088.

7. Klemm, R. D. W.; Labrique, A. B.; Christian, P.; Rashid, M.; Shamim, A. A.; Katz, J.; Sommer, A.; West, K. P.; J. Pediatr. 2008, 122, 242.

8. Gunstone, F. D.; Vegetable Oils in Food Technology: Composition, Properties and Uses, Blackwell Publishing: Oxford, 2002.

9. Arain, S.; Sherazi, S. T. H.; Bhanger, M. I.; Talpur, F. N.; Mahesar, S. A.; Thermochim. Acta 2009, 484, 1.

10. Silva, S. M.; Sampaio, K. A.; Taham, T.; Rocco, S. A.; Ceriane, R.; Meirelles, A. J.; J. Am. Oil Chem. Soc. 2009, 86, 611.

11. Ministério da Agricultura, Pecuária e Abastecimento; Regulamento Técnico de Identidade e Qualidade de Óleos Vegetais Refinados - Instrução Normativa n. 49, Brasil, 2006. DOU 26/12/2006.

12. Zanatta, C. F.; Ugartondo, V.; Mitijans, M.; Rocha-Filho, P. A.; Vinardell, M. P.; Food Chem. Toxicol. 2008, 46, 2776.

13. Durães, J. A.; Drummond, A. L.; Pimentel, T. A. P. F.; Murta, M. M.; Moreira, S. G. C.; Sales, M. J. A.; J. Therm. Anal. Calorim. 2008, 92, 529 .
14. Schlemmer, D.; Sales, M. J. A.; J. Therm. Anal. Calorim. 2010 , 99, 675.

15. Moretto, E.; Fett, R.; Tecnologia de Óleos e Gorduras Vegetais, $2^{\text {nd }}$ ed.; Varela: Rio de Janeiro, Brasil, 1989.

16. Morais, M. M.; Pinto, L. A. A.; Ortiz, S. C. A.; Crexi, V. T.; Silva, R. L., Silva, J. D.; Rev. Inst. Adolfo Lutz 2001, 60, 23.

17. Agência Nacional de Vigilância Sanitária; Métodos Físico Químicos para Análise de Alimentos, $4^{\text {th }}$ ed.; Ministério da Saúde: Brasília, Brasil, 2005.

18. AOCS - American Oil Chemists' Society; Official Methods and Recommended Practices of the American Oil Chemists'Society, $4^{\text {th }}$ ed; Association of Official Analytical Chemistis: Champaign, IL., 1997.

19. Folch, J.; Less, M.; Stanley, S. A.; J. Biol. Chem. 1957, 226, 497.

20. Hartman, L.; Lago, R.C.A.; Lab. Practice 1973, 22, 475.

21. Carvalho, P. R. N.; Collins, C. H.; Rodriguez-Amaya, D. B.; Chromatographia 1992, 33, 133.

22. Brand-Williams, W.; Cuvelier, M. E.; Berset, C.; Lebensm. Wiss. U.-Technol. 1995, 28, 25.

23. Roesler, R.; Malta, L. G.; Carrasco, L. C.; Holanda, R. B.; Sousa, C. A. S.; Pastore, G. M.; Ciênc. Tecnol. Aliment. 2007, 27, 53.

24. SPSS ${ }^{\circledR} 14.0$ for Windows Evaluation Version (Computer program); LEAD Technologies SPSS Inc.: USA, 2005.

25. Del Río, V.; Larrechi, M. S.; Callao, M. P. Talanta 2010, 81, 1572.

26. Dag, A.; Kerem,Z.; Yogev, N.;Zipori, I.; Lavee, S.; Ben-David, E.; Sci. Hortic. 2011, 127, 358.

27. Rossi, M.; Alamprese, C.; Ratti, S.; Riva, M.; Food Chem. 2009, $112,448$.

28. Ribeiro, B. D.; Nascimento R. F., Barreto, D. W.; Coelho, M. A. S.; Freitas, S. P.; Rev. Bras. Frutic. 2010, 32, 657.

29. O'Brien R. D.; Fats and Oils: Formulating and Processing for Applications, $2^{\text {nd }}$ ed., CRC Press: New York, 2004.

30. García-Quiroz, A.; Moreira, S. G. C.; Morais, A. V.; Silva, A. S.; Rocha, G. N.; Alcantara, P.; Instrum. Sci.Tech. 2003, 31, 93.

31. Verleyen, T.; Van Dyck, S.; Adams, C. A.; Accelerated Stability Tests: Analysis of Lipid Oxidation, $5^{\text {th }}$ ed.; AOCS Press: Champaign, 2005.

32. Shahidi F.; Quality Assurance of Fats and Oils, $6^{\text {th }}$ ed.; Wiley: New York, 2005.

33. Cella, R. C. F.; Regitano-D'arce, M. A. B.; Spoto, M. H. F.; Ciênc. Tecnol. Aliment. 2002, 22, 111.

34. Lima, S. M.; Bannwart, E. S.; Oliveira, R. G.; Andrade, L. H. C.; Del Ré, P. V.; Jorge, N.; Pedrochi, F.; Constantini, R.; Medina, A. N.; Baesso, M. L.; Eur. Phys. J. 2008, 153, 531.

35. Zanatta, C. F.; Mercadante, A. Z.; Food Chem. 2006, 101, 1526.

36. Gunstone, F. D.; Rapeseed and Canola Oil - Production, Processing, Properties, and Uses, Oxford: CRC Press, 2004.

37. Tan, C. P.; Che Man Y. B.; Selamat, J.; Yusoff, M. S. A.; Food Chem. 2002, 76, 385. 
38. Pardauil, J. J. R.; Souza, L. K. C.; Molfetta, F. M.; Zamian, J. R.; Geraldo, N.; Rocha Filho, G. N.; Da Costa, C. E. F.; Bioresour. Technol. 2011. doi:10.1016/j.biortech.2011.02.022

39. McClements, D.; Decker, E. A.; J. Food Sci. 2000, 65, 1270.

40. Albuquerque, M. L. S.; Guedes, I.; Alcantara Jr., P.; Moreira, S. G. C.; Vib. Spectrosc. 2003, 33, 127.

41. Ceriani, R.; Paiva, F. R.; Gonçalves, C. B.; Batista, E. A. C; Meirelles, A. J. A.; J. Chem. Eng. Data 2008, 53, 1846.
42. Rodriguez-Amaya, D. B.; Fontes Brasileiras de Carotenóides: Tabela Brasileira de Composição de Carotenóides em Alimentos, Brasília: MMA/SBF, Brasil, 2008.

43. Valavanidis, A.; Nisiotou, C.; Papageorgiou, Y.; Kremli, I.; Satravelas, N.; Zinieris, N.; Zygalaki, H.; J. Agric. Food Chem. 2004, 52, 2358.

44. Berlitz, H.-D.; Grosch, W.; Food Chem. 1999, 2, 222.

Submitted: May 7, 2011

Published online: November 17, 2011 


\title{
Additions and Corrections
}

\section{Refining of Buriti Oil (Mauritia flexuosa) Originated from the Brazilian Cerrado: Physicochemical, Thermal-Oxidative and Nutritional Implications}

\author{
Jailane de Souza Aquino, ${ }^{*}, a$ Débora C. N. de Pontes Pessoa, ${ }^{b}$ Kassandra de Lourdes G. V. Araújo, ${ }^{c}$ \\ Poliana S. Epaminondas, ${ }^{d}$ Alexandre Ricardo P. Schuler, ${ }^{e}$ Antônio G. de Souza ${ }^{f}$ and \\ Tânia Lúcia M. Stamford ${ }^{b}$ \\ ${ }^{a}$ Departamento de Nutrição (CCS), ${ }^{c}$ Departamento de Ciência e Tecnologia de Alimentos and \\ ${ }^{f}$ Departamento de Química (CCEN), Universidade Federal da Paraíba, Campus I, \\ Cidade Universitária, s/n, Castelo Branco, 58051-900 João Pessoa-PB, Brazil \\ ${ }^{b}$ Departamento de Nutrição (CCS) and ${ }^{e}$ Departamento de Engenharia Química (CTG), \\ Universidade Federal de Pernambuco, Campus Recife, s/n, Cidade Universitária, \\ 50670901 Recife-PE, Brazil \\ ${ }^{d}$ Setor de Agroindústria, Instituto Federal de Educação, Ciência e Tecnologia (IFPB), \\ Campus Sousa, Jardim Sorrilândia, 58800-970 Sousa-PB, Brazil
}

Vol. 23, No. 2, 212-219, 2012

http://dx.doi.org/10.1590/S0103-50532012000200004

Page 217, Table 3

The fatty acid palmitoleic (C16:1) was in the percentage of 19.6 on crude oil of buriti and percentage of 19.4 in refined oil from buriti.

Table 3. Fatty acids present in crude and refined buriti oils

\begin{tabular}{lcc}
\hline \multirow{2}{*}{ Fatty acids } & \multicolumn{2}{c}{ Samples } \\
\cline { 2 - 3 } & $\begin{array}{c}\text { Crude } \\
\text { buriti oil }\end{array}$ & $\begin{array}{c}\text { Refined } \\
\text { buriti oil }\end{array}$ \\
\hline Miristic acid - C 14:0 & $0.5^{\mathrm{a}}$ & $0.5^{\mathrm{a}}$ \\
Margaric acid - C 17:0 & $0.3^{\mathrm{a}}$ & $0.2^{\mathrm{a}}$ \\
Stearic acid - C18:0 & $2.3^{\mathrm{a}}$ & $3.9^{\mathrm{b}}$ \\
Total saturated fatty acids - SFA / \% & $3.1^{\mathrm{b}}$ & $4.6^{\mathrm{a}}$ \\
Palmitoleic acid - C16:1 & $19.6^{\mathrm{a}}$ & $19.4^{\mathrm{a}}$ \\
Oleic acid - C18:1 & $72.7^{\mathrm{a}}$ & $72.2^{\mathrm{b}}$ \\
Total monounsaturated fatty acids - & $92.3^{\mathrm{a}}$ & $91.6^{\mathrm{a}}$ \\
MUFA / \% & & \\
Linoleic acid - C 18:2 & $2.6^{\mathrm{a}}$ & $2.3^{\mathrm{b}}$ \\
Linolenic acid - C 18:3 & $2.0^{\mathrm{a}}$ & $1.5^{\mathrm{b}}$ \\
Total polyunsaturated fatty acids - PUFA / \% & $4.6^{\mathrm{a}}$ & $3.8^{\mathrm{a}}$ \\
\hline
\end{tabular}

Different letters on same row represent significant difference at $5 \%$ level by $t$-Student test. The values are expressed in percentage $(\%)$.
Will change to:

The fatty acid palmitic acid (C16:0) is in the percentage of 19.6 on crude oil of buriti and percentage of 19.4 in refined oil from buriti.

Table 3. Fatty acids present in crude and refined buriti oils

\begin{tabular}{lcc}
\hline \multirow{2}{*}{ Fatty acids } & \multicolumn{2}{c}{ Samples } \\
\cline { 2 - 3 } & $\begin{array}{c}\text { Crude } \\
\text { buriti oil }\end{array}$ & $\begin{array}{c}\text { Refined } \\
\text { buriti oil }\end{array}$ \\
\hline Miristic acid - C 14:0 & $0.5^{\mathrm{a}}$ & $0.5^{\mathrm{a}}$ \\
Margaric acid - C 17:0 & $0.3^{\mathrm{a}}$ & $0.2^{\mathrm{a}}$ \\
Stearic acid - C18:0 & $2.3^{\mathrm{a}}$ & $3.9^{\mathrm{b}}$ \\
Total saturated fatty acids - SFA / \% & $3.1^{\mathrm{b}}$ & $4.6^{\mathrm{a}}$ \\
Palmitoleic acid - C16:0 & $19.6^{\mathrm{a}}$ & $19.4^{\mathrm{a}}$ \\
Oleic acid - C18:1 & $72.7^{\mathrm{a}}$ & $72.2^{\mathrm{b}}$ \\
Total monounsaturated fatty acids - & $92.3^{\mathrm{a}}$ & $91.6^{\mathrm{a}}$ \\
MUFA / \% & & \\
Linoleic acid - C 18:2 & $2.6^{\mathrm{a}}$ & $2.3^{\mathrm{b}}$ \\
Linolenic acid - C 18:3 & $2.0^{\mathrm{a}}$ & $1.5^{\mathrm{b}}$ \\
Total polyunsaturated fatty acids - PUFA / \% & $4.6^{\mathrm{a}}$ & $3.8^{\mathrm{a}}$ \\
\hline
\end{tabular}

Different letters on same row represent significant difference at $5 \%$ level by $t$-Student test. The values are expressed in percentage $(\%)$. 